\title{
Carboplatin/Topotecan Regimen
}

National Cancer Institute

\section{Source}

National Cancer Institute. Carboplatin/Topotecan Regimen. NCI Thesaurus. Code C156250.

A reg imen consisting of carboplatin and topotecan with potential use in the treatment of some cancers, including small cell lung, ovarian and cervical cancer. 